\title{
How restaurant and bar owners view clean indoor air legislation five years after implementation in North Carolina, 2015
}

\author{
Ann H. Stoples', Tora L. Gallien², Ryan Martin ${ }^{3}$, Joseph Lee ${ }^{3}$, Jennifer Cremeens-Matthews ${ }^{3}$
}

\begin{abstract}
INTRODUCTION Smoke-free policies are effective in eliminating health hazards that can lead to chronic diseases and premature death. How hospitality businesses experience clean indoor air policies may provide leverage in States that have not adopted such policies. This study assessed whether North Carolina restaurants and bars receive complaints and/or experience benefits five years after implementation of the State's smoke-free law.

METHODS A 2015 mail survey was used to assess problems, benefits, and voluntary policies (i.e., policies related to the use of electronic cigarettes indoors and outside smoke-free seating areas) among restaurant and bar owners/managers. The survey yielded 135 responses for a response rate of $20.3 \%$.

RESULTS The two most frequently selected benefits among respondents were customers breathing less tobacco smoke $(65.2 \%)$ and fewer complaints about secondhand smoke (58.5\%). The majority of restaurants $(79.7 \%)$ and bars (71.4\%) reported experiencing at least one benefit from the law. Restaurants were significantly more likely than bars to restrict the use of electronic cigarettes inside. No significant difference was found between restaurants and bars in smokefree outdoor customer areas. Bars were more likely to report problems with the smoke-free law (e.g. lack of outdoor space for smoking, compliance issues).

conclusions This study reveals successes of North Carolina's smoke-free law. The majority of respondents reported experiencing at least one benefit of the law and some reported that they had implemented additional voluntary policies. Learning more about how hospitality businesses experience smoke-free laws can help other states and communities deal with similar policy changes in the future.
\end{abstract}

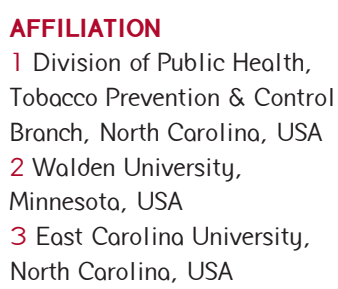

AFFILIATION

1 Division of Public Health,

Tobacco Prevention \& Control

Branch, North Corolina, USA

2 Walden University,

Minnesota, USA

3 East Carolina University,

North Carolina, USA

\section{CORRESPONDENCE TO \\ Tara L. Gallien. Walden \\ University, 101 Hearthstone Lane, \\ 27516 Chapel Hill, United States \\ E-mail: gallient868@gmail.com}

KEYWORDS

tobacco, secondhand smoke,

smoke-free legislation

Received: 22 February 2017

Revised: 12 July 2017

Accepted: 14 July 2017

\section{INTRODUCTION}

Diseases caused by cigarette smoking are the leading causes of death and disability in the United States and in North Carolina (N.C.) ${ }^{1}$. An estimated 485,000 Americans die of smoking-related illnesses annually, and one of five deaths that occur in the United States is related to cigarette smoking ${ }^{1}$. The U.S. Surgeon General definitively warned of the dangers of breathing others' secondhand tobacco smoke in $1986^{2}$. In 2006, the U.S. Surgeon General released a second report on involuntary smoking, which concluded that a person exposed to secondhand smoke at home or work has a $20 \%$ to $30 \%$ increased risk of developing lung cancer and a $25 \%$ to $30 \%$ increased risk of developing heart disease ${ }^{3}$. Even short-term exposure can cause heart $\operatorname{attack}^{4}$ or stroke ${ }^{1}$.
Smoke-free policies are interventions that, when implemented according to the evidence base, have been proven to: 1) reduce exposure to secondhand smoke, 2) reduce smoking rates, 3) increase the number of tobacco users who quit, 4) reduce the initiation of tobacco use among young people, and 5) reduce tobacco-related morbidity and mortality, including heart attacks ${ }^{5,6}$. Such policies are notably less present in the Southern U.S. compared to other areas of the country ${ }^{7}$, and adoption of smoke-free policies appears to have stalled ${ }^{8}$.

On 2 January 2010, N.C. implemented a smoke-free law that prohibits cigarette smoking (and other products that burn tobacco) inside all restaurants and bars as well as inside hotels, lodges, inns, convenience stores, and other businesses that serve prepared food ${ }^{9}$. Since its passage, restaurants have 
been receptive to the smoke-free law ${ }^{10-12}$. In contrast, N.C. bars, which are by definition private clubs under state alcohol law, generally have not shown public support for the smokefree law, and a number of bars fought and lost court battles to continue to allow smoking in their businesses ${ }^{11}$. Studies show the law has improved indoor air quality, reduced exposure to secondhand smoke at work, and improved community health status $^{13}$. Economic studies of N.C.'s smoke-free law have had consistent results with those of other States, showing no impact - positive or negative - on restaurant and bar receipts or employment patterns ${ }^{14,15}$.

How bars and restaurants experience the adoption of evidence-based clean indoor air policies may provide leverage in other Southern States that have not adopted comprehensive clean indoor air policies. No previous study has looked specifically at restaurants' and bars' response to the law five years after implementation. Documenting restaurant and bar owners'/managers' receipt of complaints from customers and employees about the law and their perception of whether the law has delivered its promised benefits, is important for public health in recommending future legislation and programming. Additionally, policy interventions targeting exterior, outdoor spaces and the use of electronic nicotine delivery systems (ENDS) could strengthen efforts to protect the health of the public. Understanding restaurant and bar owners' and managers' positions on these issues is critical to shaping future public health programs and future smoke-free and vapor-free public and private regulations.

As tobacco smoke is pushed out of restaurants and bars, nonsmoking customers are now in close proximity to smokers in many outdoor spaces, such as restaurant and bar decks and patios. The smoke-free law requires limited outdoor areas to be smoke-free, such as those that have a roof or covering and a certain percentage of enclosure. Unenclosed outdoor areas have thus become the default smoking areas of many bars and restaurants, potentially exposing patrons and employees to hazardous levels of secondhand tobacco smoke. In addition, the use of electronic cigarettes is increasing rapidly ${ }^{16}$. Adult 30 -day use has been documented nationally at $3.3 \%{ }^{17}$. The N.C. Youth Tobacco Survey documented a consistent shift from cigarette to e-cigarette use. As 30-day electronic cigarette use among N.C. high school students increased from 1.7\% in 2011 to $16.8 \%$ in 2015 , 30-day high school cigarette smoking decreased from $15.5 \%$ in 2011 to $9.3 \%$ in $2015^{18}$. While the health effects of using ENDS or involuntarily breathing their aerosol (commonly called vapor) has not been fully documented, recent studies reveal concerning levels of hazardous contents in electronic cigarette aerosol ${ }^{19-22}$.
The purpose of this study is two-fold: 1) to assess whether, after five years of implementation of the N.C. smoke-free law, restaurant and bar owners and managers receive complaints about the law and whether they are experiencing the benefits promised when the law was first passed, and 2) to explore whether they are implementing policies that go beyond what is covered in the current law, specifically prohibiting the use of electronic cigarettes indoors and/or providing smoke-free seating areas for customers outside.

\section{METHODS}

In this descriptive, cross-sectional study, we conducted a mail survey of N.C. bars and restaurants in January 2015. Two sampling frames were used to identify restaurants and bars. For restaurants, we used a N.C. Department of Health and Human Services database of restaurants that receive local sanitation inspections. In December 2014 this database, which is updated quarterly, contained 14,044 operating restaurants. We excluded: fast food restaurant chains (all of which were voluntarily smoke-free before the law went into effect in 2010); school, college or business cafeterias; churches; food and convenience stores; take-out and delivery restaurants; ice cream shops; retirement or health care facilities; camps; prisons; and caterers. Also excluded were restaurants with out-of-state mailing addresses. The final sampling frame included 8,799 records. For the bar sampling frame, we used a N.C. ABC Commission licensing list of "private clubs" meaning they both; 1) hold a license to serve alcoholic beverages for consumption on-site, and 2) do not serve prepared food (that would require health department restaurant inspections, qualifying them for the restaurant list). The database, which is updated quarterly, contained 1,165 bars in December 2014. We excluded event venues, theaters, country clubs, fraternal organizations, airline/ airport membership clubs, and organizations holding only temporary alcohol licenses. Also excluded were bars with outof-state mailing addresses and the eight cigar bars that are exempt from the law. The final sampling frame for bars was 803.

The size of the sample was determined using Fluid Surveys online sample size calculator for prevalence with $5 \%$ margin of error in a known population size (i.e. 8,799 restaurants and 803 bars $)^{23}$. Random samples were drawn using the random generator in Microsoft Excel, from two spreadsheets (one for restaurants and one for bars). Data were gathered using two 20-question pencil and paper surveys (one for restaurants and one for bars), which were mailed to random samples of 374 restaurant and 289 bar owners and managers $(n=663)$ across the state. The surveys were mailed to the "Owner or Manager" 
of each selected business and did not ask for identifying information from the individual completing the survey or the business the person represents. Participants were asked to return the completed surveys by mail using a pre-stamped return envelope that was included in the survey packet. No incentive was provided. We mailed a follow-up postcard approximately four weeks later to remind all recipients about the survey and request their participation.

\section{Instrumentation}

The questions on the two pencil and paper surveys (Appendix A, supplemental file) were divided into four sections: "Questions about the current law" (questions 1-6), "Questions about electronic cigarettes" (questions 7-11), "Questions about outside seating areas" (questions 12-14) and "Additional questions" (questions 15-20), including a final open-ended question. Questions two through five were drawn from a telephone survey conducted by Linnan et al. ${ }^{10}$. These questions assessed the owners/managers' receipt of complaints from employees and customers about current tobacco-related policies. Questions six through twenty were created by the survey team and assessed for face validity by expert reviews, including N.C. Restaurant and Lodging Association (NCRLA) staff, NCRLA members, and N.C. Tobacco Prevention and Control Branch (TPCB) staff. Feedback was used to improve the survey.

The questions on the two surveys were nearly identical. Besides referencing "bars" instead of "restaurants" the only question difference was the question that asked each participant to identify benefits the business experienced from the smokefree law. The restaurant version included "Increase in number of families coming in" as a response choice. This choice was not included on the bar survey, because bars are age-restricted businesses.

\section{Data analysis}

IBM's Statistical Package for the Social Sciences (SPSS) software was used to analyze the responses from the first 19 questions on the surveys. Descriptive statistics were used to report the demographic characteristics of participants (i.e. job title, years in the N.C. hospitality industry, and smoking and/or electronic cigarette behavior) and the other survey questions. Chi-square tests were used to determine statistical significance when comparing restaurants' and bars' current policies on the use of electronic cigarettes indoors and smokefree customer areas outdoors. The Institutional Review Board at the university where this research was conducted reviewed and exempted the study.

\section{RESULTS}

By 18 February 2015, 136 surveys had been returned. One survey was incomplete; therefore, it was not included in the analysis. The final sample was 135 , which represents a return rate of $20.3 \%$ ( $23 \%$ for restaurants and $17 \%$ for bars). Assumptions concerning the representativeness of nonrespondents are addressed in the Limitations section. The mean number of years the participants had worked in N.C.'s hospitality industry was 19 , with a median of 16.5 . Of those who completed the survey, $45.5 \%$ identified themselves as owners, $14.9 \%$ as managers, and $35.1 \%$ as owners/managers of their businesses. The remaining $3.7 \%$ reported their position as "other". The current cigarette smoking rate of the participants was $22.2 \%$, with $25.2 \%$ former smokers and $52.6 \%$ never smokers. A total of $9.6 \%$ of the participants reported having used an electronic cigarette in the last 30 days. All participants were familiar with the State's smoke-free restaurants and bars law.

\section{Complaints about law}

As shown in Table 1, reported customer and employee complaints about secondhand smoke inside restaurants and bars overall were low, but were higher for bars. Complaints about having no place to smoke were higher for bars than for restaurants. The proportions of customer complaints about electronic cigarette use indoors were identical for customers and similar for employees in both restaurants and bars.

Table 1. Frequencies and Percentages of Customerand Employee Complaints Received in the Last 12 Months, N.C., 2015

\begin{tabular}{|c|c|c|c|}
\hline Complaint & $\begin{array}{c}\text { Restaurant } \\
(n-86) \\
n(\%)\end{array}$ & $\begin{array}{c}\text { Bar } \\
(n=19) \\
n(\%)\end{array}$ & $\begin{array}{c}\text { Total } \\
(n=135) \\
n(\%)\end{array}$ \\
\hline \multicolumn{4}{|c|}{ Complaints about Secondhand Smoke } \\
\hline From Customers & $1(1.2 \%)$ & $4(8.1 \%)$ & $5(3.7 \%)$ \\
\hline From Employees & $1(1.2 \%)$ & $3(6.1 \%)$ & $4(3.0 \%)$ \\
\hline \multicolumn{4}{|c|}{ Complaints about No Place to Smoke } \\
\hline From Customers & $5(5.8 \%)$ & $32(65.3 \%)$ & $37(27.4 \%)$ \\
\hline From Employees & $5(5.8 \%)$ & $21(53.1 \%)$ & $26(19.3 \%)$ \\
\hline \multicolumn{4}{|c|}{ Complaints about Electronic Cigarettes } \\
\hline From Customers & $14(16.3 \%)$ & $8(16.3 \%)$ & $22(16.3 \%)$ \\
\hline From Employees & $8(9.3 \%)$ & $3(6.1 \%)$ & $11(8.1 \%)$ \\
\hline
\end{tabular}

\section{Benefits of low}

As shown in Table 2, the benefit experienced from the smoke-free law most selected by both restaurants and bars was "customers breathe less tobacco smoke". Nearly $80 \%$ of the participating restaurants and more than $70 \%$ of the 
Table 2. Frequencies and Percentages of N.C. Restaurant/Bar Owners Managers Reponses to Selecting Benefits from the Smoke free Law from a Preset List, 2015

\begin{tabular}{|c|c|c|c|}
\hline Benefit & $\begin{array}{l}\text { Restaurant } \\
(\mathbf{n}=86)\end{array}$ & $\begin{array}{c}\text { Bar } \\
(n=19)\end{array}$ & $\begin{array}{c}\text { Total } \\
(n=135)\end{array}$ \\
\hline $\begin{array}{l}\text { One or More Benefit(s) } \\
\text { Endorsed }\end{array}$ & $67(77.9 \%)$ & $36(73.5 \%)$ & $103(76.3 \%)$ \\
\hline $\begin{array}{l}\text { Two or More Benefit(s) } \\
\text { Endorsed }\end{array}$ & $52(60.4 \%)$ & $28(57.1 \%)$ & $80(59.3 \%)$ \\
\hline $\begin{array}{l}\text { Customers Breathe } \\
\text { Less Tobacco Smoke }\end{array}$ & $59(68.6 \%)$ & $29(59.2 \%)$ & $88(65.2 \%)$ \\
\hline $\begin{array}{l}\text { Fewer Complaints } \\
\text { About Secondhand } \\
\text { Smoke }\end{array}$ & $54(62.8 \%)$ & $25(51.0 \%)$ & $79(58.5 \%)$ \\
\hline $\begin{array}{l}\text { Decrease in } \\
\text { Maintenance/Cleaning } \\
\text { Cost }\end{array}$ & 37 (43.0\%) & 25 (51.0\%) & 62 (45.9\%) \\
\hline Improved Staff Health & $26(30.2 \%)$ & $14(28.6 \%)$ & $40(29.6 \%)$ \\
\hline $\begin{array}{l}\text { Increased Staff } \\
\text { Productivity }\end{array}$ & 18 (20.9\%) & $8(16.3 \%)$ & $26(19.3 \%)$ \\
\hline $\begin{array}{l}\text { Increase in Number of } \\
\text { Customers }\end{array}$ & $17(19.8 \%)$ & $7(14.3 \%)$ & $24(17.8 \%)$ \\
\hline $\begin{array}{l}\text { More Families Coming } \\
\text { In }\end{array}$ & 27 (31.4\%) & $\mathrm{N} / \mathrm{A}$ & - \\
\hline
\end{tabular}

participating bars reported experiencing at least one benefit from the smoke-free law.

\section{Policies on the use of electronic cigarettes indoors}

As shown in Table 3, among the restaurant owners and managers who responded to the survey, nearly half (46.1\%) reported not allowing electronic cigarettes to be used inside their business, and a fifth more reported having inside designated areas for electronic cigarettes. A much lower percentage of bars responding to the survey reported not allowing electronic cigarette use inside $(10.2 \%)$ or in indoor designated areas $(12.2 \%)$. The Chi-square analysis results indicated that indoor electronic cigarette policies differ significantly between bars and restaurants $(\mathrm{x} 2=25.065, \mathrm{p}<.001)$.

Table 3.Restaurant and Bar Policies on Indoor UseofElectronic Cigarettes, as Reported by N.C. Restaurant and BarOwners Managers, 2015

$\begin{array}{lccc}\text { Policy } & \begin{array}{c}\text { Restaurant } \\ (n-76) \\ n(\%)\end{array} & \begin{array}{c}\text { Bar }(n-19) \\ n(\%)\end{array} & \begin{array}{c}\text { Total } \\ (n-125) \\ n(\%)\end{array} \\ \begin{array}{l}\text { Not Allowed Inside } \\ \begin{array}{l}\text { Allowed in Certain Areas } \\ \text { Inside }\end{array}\end{array} & 16(21.1 \%) & 6(12.2 \%) & 22(17.6 \%) \\ \begin{array}{l}\text { Allowed Anywhere Inside } \\ \text { Total }\end{array} & 25(32.9 \%) & 38(77.6 \%) & 63(50.4 \%) \\ & 76(100 \%) & 49(100 \%) & 125(100 \%)\end{array}$

$(x 2=25.065, p<.001),{ }^{*} 10$ restaurants did not respond to this question

\section{Policies on outside seating areas for customers}

Of the 100 survey respondents reporting having outdoor areas, one-third of restaurants (33.9\%) and one-fifth of bars (21.1\%) had some sort of policy restricting smoking outdoors. Chisquare test results showed no statistically significant difference in smoking restrictions in outdoor seating areas between bars and restaurants $(\mathrm{x} 2=1.880, \mathrm{p}<0.170)$.

\section{Additional feedback}

Participants were asked to provide additional feedback not addressed in the survey. A total of 68 survey participants (50.4\%) made at least one comment. Comments were nearly evenly split, with 40 positive and 44 negative about the smoke-free law. Negative comments were almost exclusively from bars. The most interesting comments drew attention to particular issues bars were having with the smoke-free law: 1) a perception that the law is not being enforced (at their competitors), 2) a lack of outdoor space for smoking, and 3) a lack of compliance by customers.

Bar owners expressed their belief that other bars were allowing smoking, drawing customers away from the lawabiding bars. These quotes are both from bars: "This law is not followed by competitors which results in unfair business competition. Law needs more enforcement" and "Law is not enforced. Establishments are knowingly violating the law or paying fines by [accepting] donations from patrons to do so."

Approximately a quarter of survey participants reported not having an outdoor customer area. For bars, not having a place for smokers to go was described as a problem for business success under the smoke-free law. This quote is from a bar: "We would like to accommodate them by having a nice designated covered area outside, which our city will not allow. So when we have rain or bad weather it kills my business!!!"

Even five years into implementation a few bar owners/ managers noted they are having difficulty getting their customers to comply with the smoke-free law. This quote is an example from a bar: "A lot of time I have to let people still smoke just so I can make money to keep my doors open."

\section{DISCUSSION}

Earlier studies have shown that the N.C. smoke-free law has improved indoor air quality, reduced exposure to secondhand smoke at work, and improved community health status ${ }^{13}$. Additionally, economic studies examining the impacts of the law have proven similar to those in other States, showing no impact - positive or negative - on restaurant and bar receipts or employment patterns ${ }^{14,15}$. This study adds to the body of knowledge on smoke-free laws, specifically in the hospitality 
industry, by exploring the perceptions and actions of bar and restaurant owners/managers in N.C. regarding the State's smoke-free law five years into its implementation.

Most restaurants clearly perceive the impact of the law positively, and many bars also reported at least one of the law's promised benefits, such as reduced customer complaints and exposure to secondhand smoke. Nearly $60 \%$ of participants selected as a benefit "fewer complaints about secondhand smoke," which suggests that the smoke-free law has been successful in reducing both exposure to and customer complaints about secondhand smoke. A similar percentage of participants reported experiencing two or more benefits from the smokefree law and nearly 30\% reported perceived improvements in staff health as a benefit. These findings provide further evidence that the law has successfully reduced exposure to secondhand smoke to hospitality workers and patrons.

Polling data have shown high levels of public support for N.C.'s smoke-free law (at $83 \%$ in 2012 ) $^{24}$; however, this does not demonstrate complete satisfaction by bar patrons with the law. Even after five years of law implementation, bar owners and managers in the present study report having received complaints in the last 12 months from smoking customers and employees about not having a place to smoke indoors. Previous studies suggest that bar patrons who smoke will adjust to the law as time passes ${ }^{25-27}$; however, based on the findings of this study, it appears that some N.C. smokers remain unsupportive.

More than half of the participants who did not report a benefit from the law own or manage a business that either opened after the law went into effect or were smoke-free prior to the law. Restaurants and bars that adopted smoke-free policies ahead of the law may have lost a competitive edge once all restaurants and bars became smoke-free, as many smokefree restaurants and bars advertised their smoke-free status and were listed on local, state and national smoke-free dining guide websites.

This study uncovered a group of N.C. bars that continue to struggle with the smoke-free law, even five years after its launch. Many bars gave positive feedback about the law. However, there appear to be some bars in N.C. that have not made a smooth transition to smoke-free, some of them because they do not have access to an outdoor area suitable for smokers, and others because they have not changed their smoker-friendly business model.

\section{Implications for research}

This study suggests there are opportunities for future research to improve understanding of how owners' and managers' knowledge of and attitudes toward cigarette smoking may have changed over time. The participants in this study had a lower percentage of smokers (22.2\% versus $31.0 \%$ ) than were found by Linnan et al. in their study prior to passage of the law $^{10}$. In fact, the current smoking rate of survey participants was only slightly higher than the smoking prevalence among all North Carolina adults ${ }^{28}$.

In addition, this study found current (30-day) use of electronic cigarettes among survey participants was $9.6 \%$. While there are no available data for 30-day electronic cigarette use among N.C. adults, the most recent national data show a much lower rate of adult current electronic cigarette use $(3.3 \%)^{17}$. Additional data are needed on all aspects of the use of these new products, including use among restaurant/ bar employees and patrons.

Further qualitative research may help identify strategies for supporting bars in their transition to smoke-free business models. Focus groups or in-depth open-ended interviews with bar and restaurants owners and managers could be fruitful in understanding the specific issues the smoke-free law has raised, particularly for bars. This study found that some bar owners/managers noted increased business or no problems caused by the law, whereas others said the law "killed" their businesses. A qualitative research project could begin to shed understanding on what the differences are between bars that managed the change without suffering and those whose businesses suffered greatly.

\section{Implications for practice}

Results of this research show an opportunity for other Southern States to develop smoke-free restaurants and bars laws in order to move them closer to comprehensive smokefree policies as recommended by the Community Preventive Services Task Force ${ }^{5}$. The fact that nearly eight of 10 restaurant respondents and more than two-thirds of bar respondents reported experiencing at least one of the promised benefits of the smoke-free law shows potential support and cooperation from restaurants and bars in other States. Strong interest in additional tobacco-related policies should encourage N.C. public health to develop educational programs that assist restaurants and bars with restricting the use of electronic cigarettes indoors and making outdoor customer areas smokefree. According to Americans for Nonsmokers' Rights ${ }^{29}, 11$ States and 450 municipalities around the U.S. restrict the use of electronic cigarettes inside restaurants and bars. The study showed that $46.1 \%$ of restaurants already limit electronic cigarette use indoors, and $33.9 \%$ of restaurants and $21.1 \%$ of bars already have a smoking policy for outdoor customer areas. These findings suggest that programs aimed at extending 
these voluntary policies to more restaurants and bars might be well-received.

There may be an opportunity for local public health to reach out to local bars and see if there are remedies to some specific concerns raised by survey participants. Approximately a quarter of businesses responding to the survey reported having no outdoor customer areas. There may be an opportunity for local government, community colleges, or business support organizations to assist those businesses in creative solutions, including updated business models for smoke-free bars. Approaching bars that have successfully transitioned to smokefree status to document their steps for success and sharing them with others would be one way to support bars that are still struggling with the transition.

\section{Limitations}

There are several limitations to this study. Self-selection for study participation could have had a significant impact on the results. Those receiving surveys with strong feelings about the smoke-free law - either positive or negative - were possibly more likely to complete the survey than were those in the sample with neutral feelings about the law. Also, data for this study were obtained through self-report. Due to the political nature of the topic, participants may not have truthfully answered the questions on the survey. Another limitation concerns the item used to assess the health of employees, as that question relied on the perception of the employer and that person might not be able to accurately perceive the health of his/her employees. In addition, since N.C. alcohol law is unique in how it defines restaurants and bars, the results of this study might not be generalizable to any other State that may have different legal definitions of these businesses. This study has important strengths, including use of a high qualitysampling frame and random sampling. Additionally, the use of a mail survey allowed participation for those without internet access and avoided sampling bias from telephone listings, as small businesses may not have a landline.

\section{CONCLUSIONS}

Results of this study show new ways N.C.'s smoke-free law has been successful. Specifically, restaurant and bar management is familiar with the law and almost all report compliance. More than half of the restaurants and bars in the study report as benefits delivered by the law the reduced exposure to and complaints about secondhand smoke. Other benefits from the law were noted as well, particularly reduced cleaning and maintenance costs and improved staff health. Most restaurants clearly perceive the impact of the law more positively, and many bars also made positive comments and reported receiving benefits from the law.

Some bars and restaurants in N.C. have proactively implemented voluntary policies to protect the health of their patrons and employees, including smoke-free outdoor customer areas and restricting electronic cigarette use indoors. Public health and its partners should move forward with programs to promote and support these changes in order to further protect the public's health. Learning more about bars' transitions and struggles can help other States and communities to deal with similar policy changes in the future, and perhaps discover ways to facilitate hospitality businesses make the transition to cleaner air.

\section{REFERENCES}

1 U.S. Department of Health and Human Services, The Health Consequences of Smoking - 50 Years of Progress: A Report of the Surgeon General. 2014, Public Health Service, Office of the Surgeon General: Rockville, MD. doi: 10.1037/e510072014-001.

2. U.S. Department of Health and Human Services, The Health Consequences of Involuntary Smoking: A Report of the Surgeon General. 1986.

3. U.S. Department of Health and Human Services, The Health Consequences of Involuntary Exposure to Tobacco Smoke. 2006, Centers for Disease Control and Prevention, National Center for Chronic Disease Prevention and Health Promotion, Office on Smoking and Health.

4. Institute of Medicine, Secondhand Smoke Exposure and Cardiovascular Effects: Making Sense of the Evidence. 2009, National Academies Press: Washington D.C.

5. Community Preventative Services Task Force, Guide to community preventative services: Reducing tobacco use and secondhand smoke exposure - Smoke-free policies. 2012.

6. Frazer, K., et al., Legislative smoking bans for reducing harms from secondhand smoke exposure, smoking prevalence and tobacco consumption. Cochrane Database System Review, 2016. 2. doi: 10.1002/14651858.CD005992.pub2.

7. Tynan, M., et al., State and local comprehensive smoke-free laws for worksites, restaurants, and bars - United States, 2015. MMWR, 2016. 65(24): p. 623-626. doi: 10.15585/mmwr.mm6524a4.

8. Holmes, C., B. King, and S. Babb, Stuck in neutral: Stalled progress in statewide comprehensive smoke-free laws and cigarette excise taxes, United States, 2000-2014. Preventing Chronic Disease, 2016. 13(E80). doi: $10.5888 /$ pcd13.150409

9. N.C. General Assembly, Smoking Prohibited in Certain Places of Employment, N.C.G.S., Article 23 § 130A. 2009.

10. Linnan, L., et al., Views about secondhand smoke and smoke-free polices North Carolina restaurant owners before passage of law to prohibit smoking. North Carolina Medical Journal, 2010. 71(4): p. 325-333.

11. Washington, M., R. Barnes, and S. Glantz, Chipping away at tobacco 
traditions in tobacco country: Tobacco industry political interest and tobacco policy making in North Carolina 1969-2011. 2011, Center for Tobacco Research and Education, University of California at San Francisco.

12. N.C. Restaurant and Lodging Association, Letter to members of the North Carolina General Assembly. 2012.

13. N.C. Department of Health and Human Services: Tobacco Prevention and Control Branch, Evaluation of the North Carolina Smoke-Free Restaurants and Bars Law. 2013.

14. Loomis, B., P. Shafer, and M. Hasslet, The economic impact of smoke-free laws on restaurants and bars in 9 states. Preventing Chronic Disease, 2013. 10: p. 327-355. doi: $10.5888 /$ pcd10.120327.

15. Schiro, S., Evaluation of the impact of non-smoking legislation on gross collections of N.C. bars and restaurants: Comparison of pre and post-implementation of legislation. 2012.

16. Pepper, J. and N. Brewer, Electronic nicotine delivery system (electronic cigarette) awareness, use, reactions and beliefs: A systematic review. Tobacco Control, 2014. 23(5): p. 375-384. doi: 10.1136/tobaccocontrol-2013-051122.

17. Hu, S., et al. Tobacco product use among adults - United States, 2013-2014. MMWR Morbidity and Mortality Weekly Report 2016. doi:10.15585/mmwr.mm6527a1.

18. N.C. Department of Health and Human Services, North Carolina Youth Tobacco Survey (NCYTS) Middle and High School Fact Sheet. 2016.

19. Offerman, F. The hazards of e-cigarettes. ASHRAE Journal, 2014.

20. Bekki, K., et al., Carboyl compounds generated from electronic cigarettes. International Journal of Environmental Research and Public Health, 2014. 11: p. 11192-11200. doi:10.3390/ijerph111111192.

21. Williams, M., et al. Metal and silicate particles including nanoparticles are present in electronic cigarette cartomizer fluid and aerosol. PLoS One, 2013. 8, e57987.

doi:10.1371/journal.pone.0057987

22. Schober, W., et al., Use of electronic cigarettes (e-cigarettes) impairs indoor air quality and increases FeNO levels of e-cigarette consumers. International Journal of Hygiene and Environmental Health, 2014. 217(6): p. 628-637.

doi: 10.1016/j.ijheh.2013.11.003.

23. Fluid Surveys, Survey Sample Size Calculator. 2014: Ottawa, ON.

24. Bolger, G., North Carolina state-wide survey: Key findings memo. 2012, Public Opinion Strategies.

25. Borland, R., et al., Support for and reported compliance with smokefree restaurants and bars by smokers in four countries: Findings from the International Tobacco Control (ITC) Four Country Survey. Tobacco Control, 2006. 15(Suppl 3): p. iii34-iii41.

doi: $10.1136 /$ tc.2004.008748.

26. Satterlund, T., J. Lee, and R. Moore, Changes in smoking-related norms in bars resulting from California's smoke-free workplace act. Journal of Drug Education, 2013. 42(3): p. 315-326. doi: 10.2190/DE.42.3.d.

27. Tang, H., et al., Changes of attitudes and patronage behaviors in response to smoke-free bar law. American Journal of Public Health, 2003. 93(4): p. 611-617.

doi: 10.2105/ajph.93.4.611.
28. N.C. State Center for Health Statistics. North Carolina Behavioral Risk Factor Surveillance System (NC BRFSS). 2015; Available at: http://www.schs.state.nc.us/schs/brfss/ (accessed 22 Februery 2017).

29. Americans for Nonsmokers' Rights, States and Municipalities with Laws Regulating Use of Electronic Cigarettes. 2016.
ACKNOWLEDGEMENTS

The manuscript is part of a Master's thesis of East Carolina University.

CONFLICT OF INTERESTS The authors have completed and submitted the ICMUE Form for Disclosure of Potential Conflicts of Interest and none were reported.

FUNDING

There was no source of funding for this research.

PROVENANCE AND PEER REVIEW

Not commissioned externally peer reviewed 